\title{
Self-Selection and the Impact of Migration on Earnings*
}

Ricardo R. G. Avelino**

\begin{abstract}
This paper formulates and estimates a comparative advantage model of migration in which individuals maximize the value of log earnings, net of moving costs, by choosing between a pair of locations. Using a subsample of males from the 2003 wave of the PNAD, a comprehensive Brazilian national household survey, I construct six measures to assess the impact of migration on earnings. The results do not support the common notion that migrants constitute a positive selected subsample of the population, i.e., that they have unobservable traits which make them more productive than non-migrants at the destination, after controlling for observable characteristics.
\end{abstract}

Keywords: Migration, Self-selection, Roy model, Two-step estimation.

JEL Codes: C34, R23.

${ }^{*}$ Submitted in June 2011. Revised in August 2011. I gratefully acknowledge the helpful comments from two anonymous referees. All remaining errors are mine.

** Department of Economics, Universidade de São Paulo. Av. Prof. Luciano Gualberto, 908 Cidade Universitária, 05508-900 São Paulo, SP Brazil. E-mail: avelino@usp.br 


\section{Introduction}

Human capital theory views migration as a form of investment. It posits that individuals have an incentive to move if the expected stream of earnings at the destination, net of moving costs, exceeds the value at the origin (Sjaastad, 1962). Since observed earnings are influenced by locational choices, the increase in earnings attributable to migration may be a consequence of the failure to take account of sorting out.

In the context of internal migration in Brazil, Santos Jr et al. (2005) analyze the impact of the migration decision on earnings, building on the previous work of Chiswick $(1978,1999)$ and Borjas (1987). They estimate an earnings equation controlling for all observed characteristics which could potentially affect wages and conclude that the remaining differential in earnings of migrants and non-migrants must be due to unobserved factors such as motivation and entrepreneurship.

Their approach implicitly ignores a central feature of modern labor markets. Distinct regions may concentrate jobs that require different amounts and types of skills possessed by workers, captured not only by diverse demographic categories, but also by unobserved characteristics which can in principle be priced differently in geographically separated labor markets. In their model, if migrants receive a higher compensation than non-migrants at the destination, they would also have a higher compensation than stayers at the origin under the unobservable counterfactual outcome.

This paper presents and estimates a model of comparative advantage or selfselection based on a joint outcome/decision model, which dates back to Roy (1951), Willis and Rosen (1979) and Heckman and Sedlacek (1985). Stochastic outcomes consist of a pair of earnings equations at the origin and at the destination and agents choose their migration status based on the potential increase in earnings, net of moving costs, triggered by a movement. A reduced form equation that proxies the selection mechanism estimates the likelihood of migration of each individual and this probability is used to control for unobserved heterogeneity in earnings.

Tunali (2000) applies a similar framework to a rich dataset from Turkey to examine whether migration flows are consistent with the hypothesis that individuals behave rationally. I employ the six measures proposed by him to assess the impact of migration on earnings. Each measure answers a different economic question. The average earnings gain, for instance, is simply the expected increase in log earnings that would accrue to an individual randomly selected in the population if she decides to migrate. It collapses to the "effect of migration on earnings" estimated by Santos Jr et al. (2005) under the special assumption of common unobservables and same coefficients of the explanatory variables at the origin and at the destination, i.e., under the assumption of an efficiency units model.

I estimate the comparative advantage model of migration using a subsample of males from the 2003 wave of the PNAD, a comprehensive Brazilian national household survey. The choice of the 2003 wave of PNAD enables us to adjust 
the average hourly wage across states by differences in the cost of living, using the index computed by Menezes et al. (2007), which is based on the Household Budget Survey conducted by the Brazilian Institute of Geography and Statistics (IBGE) in 2002-2003.

My findings point to positive returns to migration and negative returns to staying. That is, migrants receive a higher compensation at the destination than what they would receive at the origin under the counterfactual outcome, while stayers receive a lower compensation than what they would earn had they decided to migrate. These results are consistent with the hypothesis that migration is based on a rational decision, dictated by the maximization of the logarithm of earnings, net of moving costs.

Other interesting measures of the impact of migration on earnings are the sorting gains to migration and staying, which give, respectively, the differences between the average realized earnings and the returns to migration and staying. The estimated sorting gains are negative and do not support the claim that migrants constitute a positively selected subsample of the population, i.e., that they have unobservable characteristics which make them more productive than non-migrants at the destination, after controlling for observables.

The remainder of the paper is organized as follows. In Section 2, I describe the micro dataset used in this study and present some stylized facts, highlighting the dispersion in earnings across states and the influence of covariates on the probability of migration. Section 3 develops the theoretical model, considers its estimation by a two-step procedure and discusses six measures that summarize the impacts of migration on earnings. Section 4 presents the empirical estimates and analyzes the issue of self-selection of migrants. Finally, Section 5 concludes.

\section{Migration Data and Movements across Regions}

The data used in this study consist of a subsample from the 2003 wave of the PNAD. Before presenting the theoretical model of migration in Section 3, I describe the methodology of the survey and the information available in connection with the migration patterns.

\subsection{The PNAD Survey and the Construction of the Subsample}

The PNAD, conducted by IBGE, is a nationwide survey that interviews more than 110,000 households throughout the country, with the exception of northern rural areas. It was initially fielded in 1967 and on an annual basis since $1976 .{ }^{1}$ The survey selects dwellings from the states of the country with different probabilities and draws the sample from the selected dwellings according to a probabilistic scheme in multiple stages.

\footnotetext{
${ }^{1}$ The PNAD was not carried out in 1980, 1991 and 2000, when the IBGE conducted the Census, and in 1994.
} 
The PNAD gathers information on a broad range of variables such as employment, income, educational attainment, labor force participation, marital status, and geographic residence. Since 1992, when there was a major revision in the questionnaire, the IBGE has begun to collect information on migration.

The focus of the analysis is on a subsample of males aged between 18 and 65 who were employed at the time they were interviewed. ${ }^{2}$ I believe that for this particular group the model of individual migration decision, developed in Section 3 , provides a good approximation to the actual problem faced by the agents. In this subsample, for example, wife's income on average accounts for $34.52 \%$ of the gains in $36.22 \%$ of the families. In the remaining $63.78 \%$ of the cases, wife's income does not contribute at all to total family income, providing evidence that husband's gains of migrating exceed by far wife's losses.

\subsection{Movements across Regions and the Importance of Demographic Variables}

For the purposes of this study, a person is defined as a migrant if she lived in 2003 in a state different from the state where she was born. ${ }^{3}$ Table 1 shows the fraction of stayers and migrants living in each of the states in the subsample used. ${ }^{4}$

The fraction of stayers is highest in the Northeast, which is the country's least developed region. It ranges from $85.18 \%$ in Maranhão to $94.36 \%$ in Ceará. The percentage of stayers sharply declines in the Southeast, which is the richest region. In São Paulo, for instance, migrants constitute almost one third of the population in the subsample. ${ }^{5}$

Since direct measures of mobility costs are not available, it is worthwhile to evaluate how observable characteristics help in predicting the probability of migration. Table 2 displays the fraction of migrants for four distinct educational categories. The share of people that reside in a state distinct from the place of birth shows a moderate reduction as we move to the more educated group, going

\footnotetext{
${ }^{2}$ People aged 10-18 years are excluded because most of the transitions during childhood are motivated by the relocation decisions of the parents. On the other hand, I conjecture that movements of individuals older than 65 are in general not motivated by differences in potential $\log$ earnings, since the majority of them (63.54\%) are out of the labor force.

${ }^{3}$ In principle, a more refined analysis that takes into account the possibility of multiple transitions for a given individual and that formulates the problem dynamically can offer valuable insights. However, it is precluded by the recorded procedures of the PNAD, which does not report explicitly all the movements across states. The complete history of an individual is in general unknown.

${ }^{4}$ All statistics reported in this paper take into account the PNAD probabilistic scheme, that is, they weight each of the 75,513 observations contained in the subsample by the probability of inclusion in the survey.

${ }^{5}$ Regional economic differences are pronounced in Brazil. Although $21.81 \%$ of the population lived in São Paulo in 2000, it was responsible for $33.67 \%$ of the gross domestic product (GDP). In contrast, the less developed Northeast accounted for $24.81 \%$ of the population and for only $13.09 \%$ of the GDP.
} 
from $22.68 \%$ for those with less than 4 years of schooling to $17.81 \%$ for individuals with at least a high school degree.

Table 1

Percentage of stayers and migrants residing in each of the states

\begin{tabular}{|c|c|c|}
\hline State & Stayers (\%) & Migrants (\%) \\
\hline Rondônia & 25.96 & 74.04 \\
\hline Acre & 82.40 & 17.60 \\
\hline Amazonas & 77,80 & 22.24 \\
\hline Roraima & 30.72 & 69.28 \\
\hline Pará & 70.61 & 29.39 \\
\hline Amapá & 51.51 & 48.49 \\
\hline Tocantins & 56.27 & 4.37 \\
\hline Maranhão & 85.18 & 14.82 \\
\hline Piauí & 90.84 & 9.16 \\
\hline Ceará & 94.36 & 5.64 \\
\hline Rio Grande do Norte & 89.44 & 10.56 \\
\hline Paraíba & 90.98 & 9.02 \\
\hline Pernambuco & 90.83 & 9.17 \\
\hline Alagoas & 90.58 & 9.42 \\
\hline Sergipe & 86.79 & 13.21 \\
\hline Bahia & 91.42 & 8.58 \\
\hline Minas Gerais & 90.95 & 9.05 \\
\hline Espírito Santo & 75.65 & 24.35 \\
\hline Rio de Janeiro & 80.95 & 19.05 \\
\hline São Paulo & 68.67 & 31.33 \\
\hline Paraná & 78.71 & 21.29 \\
\hline Santa Catarina & 82.68 & 17.32 \\
\hline Rio Grande do Sul & 95.13 & 4.87 \\
\hline Mato Grosso do Sul & 61.06 & 38.94 \\
\hline Mato Grosso & 36.25 & 63.75 \\
\hline Goiás & 67.42 & 32.58 \\
\hline Distrito Federal & 26.97 & 73.03 \\
\hline Total & 79.51 & 20.49 \\
\hline
\end{tabular}

This table shows the percentage of stayers and migrants for each of the Brazilian states. A person is defined as a migrant if, according to PNAD, she lives in 2003 in a state different from the state where she was born. Otherwise, she is classified as a stayer. State corresponds to the state of residence in 2003. 
Table 2

Percentage of stayers and migrants by educational category

\begin{tabular}{ccc}
\hline Years of Schooling & Stayers (\%) & Migrants (\%) \\
\hline $0-3$ & 7.32 & 22.68 \\
$4-7$ & 78.15 & 21.85 \\
$8-10$ & 79.36 & 20.64 \\
11 or more & 82.19 & 17.81 \\
\hline
\end{tabular}

This table presents the fraction of stayers and migrants for four different educational categories in 2003 Years of schooling is based on the number of years of formal schooling reported by the individuals.

The difference in the fraction of migrants is more manifested among the six cohorts and it is examined in Table 3. The participation of migrants gradually increases from $13.69 \%$ for people aged $18-25$ to $26.29 \%$ for the elderly group. We can see that although the percentage of migrants rises, it does so at a decreasing rate, suggesting that most of the transitions occur during the early adult years.

Table 3

Percentage of stayers and migrants by cohort

\begin{tabular}{ccc}
\hline Years of Schooling & Stayers (\%) & Migrants (\%) \\
\hline $18-25$ & 86.31 & 13.69 \\
$26-33$ & 80.28 & 19.72 \\
$34-41$ & 78.34 & 21.66 \\
$42-49$ & 76.58 & 23.42 \\
$50-57$ & 73.70 & 26.30 \\
$58-65$ & 73.71 & 26.29 \\
\hline
\end{tabular}

This table presents the fraction of stayers and migrants for six different cohorts in 2003.

Table 4 contains the average hourly wage for stayers and migrants in each of the states of the country under the heading unadjusted average wage. In 2003, the wage in the Northeast varied between $\mathrm{R} \$ 9.55$ in Piauí and $\mathrm{R} \$ 13.50$ in Sergipe. Earnings of workers were substantially higher in the Southeast, especially in São Paulo, where the average wage was $\mathrm{R} \$ 25.54$. It is also important to make a distinction between migrants and stayers. In general, migrants receive a higher compensation than stayers $(\mathrm{R} \$ 21.50$ compared with $\mathrm{R} \$ 18.50)$.

The last three columns of the table adjust the average hourly wage for differences in the cost of living across the states using the index computed by Menezes et al. (2007), following the suggestion of one referee. ${ }^{6}$ The incorporation of differences in the cost of living increases the average wage in the North and in the

${ }^{6}$ The index is based on the Household Budget Survey carried out by IBGE in 2002-2003 and reflects differences in rental costs across the states, not in the cost of living. However, the authors show that the index has a high correlation with the cost of living index computed by Azzoni et al. (2002), which is restricted to 11 metropolitan areas. 
Northeast and leads to a decline in earnings in the Southeast and in the Federal District. According to the table, the adjusted wage in São Paulo is only $5 \%$ greater than the national average, while adjusted earnings in the Federal District are slightly lower than the national average. Henceforth, the analysis will be conducted taking the adjusted average hourly wage as the measure of earnings.

\section{A Generalized Roy Model of the Migration Flows among the States}

In this section, I present a theoretical model aimed at assessing the influence of observable covariates and unobservable characteristics on earnings of migrants and stayers and on the migration decision. Then, I consider consistent estimation of the parameters and, at the end, I set forth six measures to evaluate the issue of self-selection and to quantify the impact of migration on earnings.

\subsection{Description of the model}

Suppose there are two potential outcomes $y_{0}$ and $y_{1}$, which can be interpreted, respectively, as potential log earnings at the origin and at the best destination. They are assumed to be an additively separable linear function of a set of observed characteristics $x$ and of an idiosyncratic shock $u_{i}$, independent of $x$, i.e,

$$
\begin{gathered}
y_{i}=x \beta_{i}+u_{i}, \quad i=0,1 \\
x \Perp u_{i} \quad i=0,1
\end{gathered}
$$

The contemporaneous values of the idiosyncratic shocks are known by the agent at the time she makes her decision, but unobservable to the econometrician. I follow much of the literature in labor economics and adopt an augmented Mincer specification for the observable component. Log earnings are not necessarily linear in schooling and, in addition to education, experience and experience squared, $x$ may include other variables that are thought to explain the dispersion in earnings, such as occupation, race and union status. ${ }^{7}$

If a person experiences a low wage offer at the origin and decides to move, she faces direct and indirect costs. The former includes the increase in expenditure for food, lodging, and transportation. The latter is comprised of foregone earnings while traveling, of the time spent at the destination searching for and learning a new job and of psychic costs such as unfamiliarity with the destination.

I model moving costs also as an additively separable linear function, according to

${ }^{7}$ See Heckman et al. (2002) for a discussion of the foundations and key implications of the Mincer earnings model. The Mincer specification implies concavity of log earnings, age and experience profiles, and parallelism in log earnings with respect to different levels of education. The authors point out that some features implied by this specification have been rejected for the U.S. in the last decades. 
Table 4

Average hourly wage for the whole population, stayers and migrants in each of the states $(\mathrm{R} \$)$

\begin{tabular}{ccccccc}
\hline State & \multicolumn{2}{c}{ Unadjusted average wage } & \multicolumn{3}{c}{ Adjusted Average Wage } \\
& Population & Stayers & Migrants & Population & Stayers & Migrants \\
\hline RO & 18.25 & 17.32 & 18.58 & 26.08 & 24.74 & 26.55 \\
AC & 18.70 & 15.56 & 33.40 & 40.50 & 33.70 & 72.36 \\
AM & 16.21 & 15.17 & 19.84 & 27.19 & 25.45 & 33.27 \\
RR & 21.88 & 24.10 & 20.90 & 29.63 & 32.63 & 28.29 \\
PA & 14.28 & 13.84 & 15.35 & 25.13 & 24.34 & 27.01 \\
AP & 20.58 & 19.16 & 22.10 & 32.83 & 30.56 & 35.25 \\
TO & 15.79 & 11.19 & 21.72 & 28.55 & 20.22 & 39.26 \\
MA & 10.50 & 10.05 & 13.11 & 23.82 & 22.79 & 29.74 \\
PI & 9.55 & 9.52 & 9.82 & 21.25 & 21.19 & 21.85 \\
CE & 10.26 & 9.87 & 16.70 & 21.93 & 21.10 & 35.71 \\
RN & 11.74 & 10.87 & 19.14 & 21.31 & 19.72 & 34.73 \\
PB & 10.90 & 9.88 & 21.25 & 22.74 & 20.60 & 44.32 \\
PE & 11.97 & 11.20 & 19.67 & 19.23 & 17.98 & 31.60 \\
AL & 11.87 & 11.02 & 20.11 & 23.96 & 22.23 & 40.57 \\
SE & 13.50 & 13.14 & 15.88 & 29.22 & 28.44 & 34.36 \\
BA & 13.05 & 12.47 & 19.23 & 20.59 & 19.67 & 30.34 \\
MG & 16.18 & 15.59 & 22.10 & 21.21 & 20.44 & 28.97 \\
ES & 16.22 & 16.21 & 16.26 & 20.35 & 20.34 & 20.40 \\
RJ & 24.43 & 23.96 & 26.43 & 27.16 & 26.64 & 29.39 \\
SP & 25.54 & 28.03 & 20.09 & 25.54 & 28.03 & 20.09 \\
PR & 21.35 & 19.11 & 29.62 & 30.30 & 27.12 & 42.04 \\
SC & 23.46 & 23.42 & 23.67 & 25.67 & 25.63 & 25.90 \\
RS & 24.26 & 23.99 & 29.62 & 31.85 & 31.49 & 38.88 \\
MS & 18.62 & 14.80 & 24.60 & 25.03 & 19.90 & 33.08 \\
MT & 17.29 & 15.06 & 18.55 & 19.38 & 16.88 & 20.79 \\
GO & 17.09 & 16.42 & 18.50 & 23.01 & 22.09 & 24.90 \\
DF & 34.23 & 32.15 & 35.00 & 23.57 & 22.14 & 24.10 \\
\hline Total & 19.12 & 18.50 & 21.50 & 24.65 & 24.17 & 26.52 \\
\hline & & & & & &
\end{tabular}

This table shows the average hourly wage for stayers, migrants and the whole population residing in each of the Brazilian states in 2003. The state corresponds to the state of residence in 2003. The unadjusted average hourly wage equals earnings from all jobs in the week in which the survey was conducted divided by the number of hours worked in the same week. The adjusted average hourly wage adjusts for differences in rental costs across states. 


$$
\begin{gathered}
C=z \tilde{\gamma}+\tilde{v} \\
z \Perp \tilde{v}
\end{gathered}
$$

where $\tilde{v}$ represents an idiosyncratic shock known to the agent, but unobservable to the econometrician, and $z$ is a set of explanatory variables. We can allow, for instance, for state dependence, through the inclusion of the spell length in the current location among the components of $z$.

The actual outcome $y$ observed by the analyst is a function of the potential outcomes and of the unobserved costs. The agent chooses to work in the location in which her income, net of moving costs, is maximized. Letting

$$
I^{*}=y_{1}-y_{0}-C=Z \gamma+v
$$

where $Z=\{x \cup z\}$, we observe

$$
y=y_{1} \Leftrightarrow I^{*} \geq 0
$$

Otherwise, we observe $y=y_{0} \cdot{ }^{8}$

\subsection{Consistent estimation of the parameters}

The error terms are allowed to be correlated across alternatives and costs. Specifically, the vector of shocks $u=\left(u_{1}, u_{0}, v\right)^{\prime}$ is assumed to follow a trivariate normal distribution with mean 0 and covariance matrix $\Sigma$, given by

$$
\Sigma=\left(\begin{array}{ccc}
\sigma_{11} & \sigma_{10} & \sigma_{1 v} \\
\sigma_{10} & \sigma_{00} & \sigma_{0 v} \\
\sigma_{1 v} & \sigma_{0 v} & 1
\end{array}\right)
$$

Note that the variance of the disturbance in the index equation is normalized to one, since the parameter $\gamma$ in the decision rule is estimable only to a scale factor. by

It is easily seen that the probability that an individual chooses sector 1 is given

$$
P\left(I^{*} \geq 0\right)=P(v \geq-Z \gamma)=\Phi(Z \gamma)
$$

where $\Phi$ denotes the cumulative distribution function of the standard normal.

Then, using standard results from the self-selection literature (see, for example, Heckman and Honore, 1990), we can express the mean of log wages observed in sector 1 as

\footnotetext{
${ }^{8}$ Since the random disturbances are assumed to have a continuous joint density function with respect to Lebesgue measure, ties occur in a negligible set.
} 


$$
E\left(y_{1} \mid I^{*}>0\right)=x \beta_{1}+\sigma_{1 v} \lambda(Z \gamma)
$$

where

$$
\lambda(Z \gamma)=\frac{\phi(Z \gamma)}{\Phi(Z \gamma)}
$$

and $\phi$ stands for the density of the standard normal.

Similarly, for sector 0, we have,

$$
E\left(y_{0} \mid I^{*}<0\right)=x \beta_{0}-\sigma_{0 v} \lambda(-Z \gamma)
$$

Therefore, ordinary least squares yields inconsistent estimates of the parameters of the earnings equations because of selection bias, unless $\sigma_{i v}=0, i=0,1$. Following Heckman (1979), I apply a two-step procedure to consistently estimate the parameters of the model. In the first step, I use the whole sample of workers to run a probit model and obtain consistent estimates of $\gamma$. Then I construct the quantities $\lambda(Z \hat{\gamma})$ and $\lambda(-Z \hat{\gamma})$. These quantities are used as an input in the second stage, which estimates equations (2) and (3) below by ordinary least squares.

$$
\begin{gathered}
y_{1}=x \beta_{1}+\sigma_{1 v} \lambda(Z \gamma)+\varepsilon_{1} \\
y_{0}=x \beta_{0}-\sigma_{0 v} \lambda(-Z \gamma)+\varepsilon_{0}
\end{gathered}
$$

$\varepsilon_{1}$ and $\varepsilon_{0}$ are the new mean-zero disturbances:

$$
\begin{gathered}
\varepsilon_{1}=u_{1}-\sigma_{1 v} \lambda(Z \gamma) \\
\varepsilon_{0}=u_{0}+\sigma_{0 v} \lambda(-Z \gamma)
\end{gathered}
$$

I replace $\lambda(Z \gamma)$ and $\lambda(-Z \gamma)$ by $\lambda(Z \hat{\gamma})$ and $\lambda(-Z \hat{\gamma})$ and use in each case only the subsample of workers observed in the region. This two-step procedure gives us estimates of $\gamma, \beta_{1}, \beta_{0}, \sigma_{1 v}$ and $\sigma_{0 v}$. The standard errors reported in the empirical section take into account the heteroskedasticity of the errors in equations (2) and (3) and the fact that the inverse Mills ratio is based on an estimated coefficient rather than on the true value. ${ }^{9}$

To recover $\sigma_{11}$ and $\sigma_{00}$, we have to use the formulas for the second moments of a truncated normal distribution

$$
E\left(u_{1}^{2} \mid I^{*}>0\right)=\sigma_{11}+\sigma_{1 v}^{2} Z \gamma \lambda(Z \gamma)
$$

\footnotetext{
${ }^{9}$ See Newey and McFadden (1994), Section 6, for the derivation of the standard errors of the parameters in the case of a random sample.
} 


$$
E\left(u_{0}^{2} \mid I^{*}<0\right)=\sigma_{00}-\sigma_{0 v}^{2} Z \gamma \lambda(-Z \gamma)
$$

Then, from the vector of squared residuals $\hat{u}_{1}^{2}$ and $\hat{u}_{0}^{2}$ obtained in the second step, we can obtain consistent estimates of $\sigma_{11}$ and $\sigma_{00}$ from

$$
\hat{\sigma}_{11}=\frac{1}{N_{1}} \sum_{i=1}^{N_{1}}\left[\hat{u}_{1 i}^{2}-\hat{\sigma}_{1 v}^{2} Z_{i} \hat{\gamma} \lambda\left(Z_{i} \hat{\gamma}\right)\right]
$$

and

$$
\hat{\sigma}_{00}=\frac{1}{N_{0}} \sum_{i=1}^{N_{0}}\left[\hat{u}_{0 i}^{2}+\hat{\sigma}_{0 v}^{2} Z_{i} \hat{\gamma} \lambda\left(-Z_{i} \hat{\gamma}\right)\right]
$$

where $N_{1}$ and $N_{0}$ denote, respectively, the number of individuals who migrated and who live in the state of origin.

The covariance between $u_{1}$ and $u_{0}, \sigma_{10}$, is not identified, because the move and stay options are mutually exclusive. For each individual we only observe the wage in the state where the agent lives.

\subsection{The impact of migration on earnings}

Given the estimates from the theoretical model, I make use of several formal criteria, proposed by Tunali (2000) and summarized in Table 5, to evaluate the impact of migration on earnings. Let

$$
\mu_{i}=x \beta_{i}, \quad i=0,1
$$

and

$$
I=1 \Leftrightarrow I^{*}>0
$$

Using expression (1), $i=0,1$, the actual outcome can be rewritten in terms of the switching regression model of Quandt (1972):

$$
\begin{aligned}
y & =(1-I) y_{0}+I y_{1} \\
& =\mu_{0}+\delta I+u
\end{aligned}
$$

where

$$
\delta=\mu_{1}-\mu_{0}
$$

and

$$
u=u_{0}+I\left(u_{1}-u_{0}\right)
$$


The first criterion consists of $\delta$, which is referred to as the average realized gain. To understand the information conveyed by $\delta$, suppose that we randomly select an individual in the population and calculate the expected difference in the potential outcomes in sectors 1 and 0 , conditional on the observed covariates. This would give us the expectation of the individual treatment effect in the terminology of the treatment effect literature. $\delta$ simply averages the expectations of the individual treatment effects across all individuals in the population, giving the average realized gain or, equivalently, the average treatment effect. Even if $\delta>0$, we cannot conclude that migrants constitute a positive selected subsample of the population, since $\delta>0$ does not imply that the mean of unobservables of migrants at the destination exceeds the population mean. $\delta$ is the measure emphasized, for example, by Santos Jr et al. (2005) under the assumptions that both earnings equations have the same variables and coefficients and that $u_{1}=u_{0}$ or, in other words, under the assumption of an efficiency units model.

Table 5

Measures of the impact of migration on log earnings

\begin{tabular}{cc}
\hline Statistic & Definition \\
\hline Average realized gain & $E\left(y_{1}-y_{0}\right)=\mu_{1}-\mu_{0}=\delta$ \\
Returns to migration & $E\left(y_{1}-y_{0} \mid I=1\right)=\mu_{1}-\mu_{0}+E\left(u_{1}-u_{0} \mid I=1\right)=\delta+E\left(u_{1}-u_{0} \mid I=1\right)=\delta_{1}$ \\
Returns to staying & $E\left(y_{0}-y_{1} \mid I=0\right)=\mu_{0}-\mu_{1}+E\left(u_{0}-u_{1} \mid I=0\right)=-\delta+E\left(u_{0}-u_{1} \mid I=0\right)=\delta_{0}$ \\
Selection of migrants & $E\left(y_{1} \mid I=1\right)-E\left(y_{1} \mid I=0\right)=E\left(u_{1} \mid I=1\right)-E\left(u_{1} \mid I=0\right)=\psi_{1}$ \\
Selection of stayers & $\left.E\left(y_{0} \mid I=0\right)-E\left(y_{0} \mid I=1\right)=E\left(u_{0} \mid I=0\right)-E\left(u_{0} \mid I=1\right)=\psi_{0}=0\right)$ \\
Earnings differential & $E\left(y_{1} \mid I=1\right)-E\left(y_{0} \mid I=0\right)=\mu_{1}-\mu_{0}+E\left(u_{1} \mid I=1\right)-E\left(u_{0} \mid I=0\right)$ \\
in favor of migrants & $=\psi_{1}-\delta_{0}=\delta_{1}-\psi_{0}$ \\
\hline
\end{tabular}

This table presents six measures of the impact of migration on earnings. Under the heading Definition, $y_{1}$ and $y_{0}$ refer, respectively, to the logarithm of the hourly wage at the destination and at the origin. $u_{1}$ and $u_{0}$ denote, respectively,

A related, but different measure, which is termed in this paper the returns to migration, compares mean earnings of migrants under the actual choice with what migrants would receive, on average, under the counterfactual choice:

$$
\delta_{1}=E\left(y_{1} \mid I=1\right)-E\left(y_{0} \mid I=1\right)=\delta+E\left(u_{1} \mid I=1\right)-E\left(u_{0} \mid I=1\right)
$$

This measure corresponds to the treatment on the treated and explicitly recognizes that individuals are not randomly assigned to their migration status. $\delta_{1}$, similarly to $\delta$, weights the individual expected gains; however, only for those individuals who decided to migrate. Obviously, $\delta_{1}$ is simply the sum of $\delta$ and of the difference in the unobservables of migrants. Assuming perfect foresight, we expect $\delta_{1}$ to be positive, since $\delta_{1}>0$ is a necessary, although not sufficient, condition for migration to take place.

A similar measure, called returns to staying, often referred to as treatment on the untreated, compares the earnings of stayers at the origin with what they would receive had they decided to migrate. It is important to stress that a negative value of $\delta_{0}$ is consistent with the hypothesis that migration is a rational decision, since $\delta_{0}$ does not take into account the costs involved in the decision to relocate. 


$$
\delta_{0}=E\left(y_{0} \mid I=0\right)-E\left(y_{1} \mid I=0\right)=-\delta+E\left(u_{0} \mid I=0\right)-E\left(u_{1} \mid I=0\right)
$$

I turn now to a measure informative of the selection of migrants, based on the difference between the unobservables of migrants and of stayers at the destination:

$$
\psi_{1}=E\left(u_{1} \mid I=1\right)-E\left(u_{1} \mid I=0\right)
$$

As mentioned earlier, migrants are said to constitute a positive selected subsample of the population if $\psi_{1}>0$. Contrary to what is stated by Tunali (2000), rationality does not imply that $\psi_{1}$ must be positive. Under the maintained assumption that agents maximize log earnings, net of moving costs, it is perfectly plausible to have $\psi_{1}<0$ if, for example, $u_{1}$ and $u_{0}$ are highly correlated so that $\sigma_{10}>\sigma_{11} / \sigma_{00}$ and $\sigma_{11}<\sigma_{00}$. In the extreme, when $u_{1}$ and $u_{0}$ are perfectly correlated, all migrants come from the lower tail of the income distribution. The stayers would also be the highest paid migrants if they were exogenously assigned to the counterfactual state. See Heckman and Sedlacek (1985) for a detailed discussion of the possible patterns in the absence of moving costs and Borjas (1987) for the general case.

Analogously, we can construct a measure based on the difference between the average outcome of stayers at the origin and what migrants would receive at the origin had they remained in their state of birth:

$$
\psi_{0}=E\left(u_{0} \mid I=0\right)-E\left(u_{0} \mid I=1\right)
$$

This tells us about the selection of stayers. If $\psi_{0}>0$, self-selection implies that stayers have higher earnings at the origin than the population mean. Otherwise, stayers have lower earnings. I note in passing that it is also possible to show, using the reasoning outlined above, that $\psi_{0}<0$ is consistent with the paradigm of a rational individual.

Finally, it is possible to compute the earnings differential in favor of migrants, denoted by $\theta$. $\theta$ compares the earnings of a typical migrant with the earnings of an average stayer and, unlike $\delta$, incorporates the effect of unobserved heterogeneity.

$$
\theta=E\left(y_{1} \mid I=1\right)-E\left(y_{0} \mid I=0\right)
$$

Clearly, the earnings differential in favor of migrants can be obtained either as the difference between the selection of migrants and the returns to staying or as the difference between the returns to migration and the selection of stayers.

\section{Empirical Results}

This section presents the estimates of the parameters of the generalized Roy model discussed in the previous section and uses the estimates to compute a variety of measures such as the returns to migration, the average realized earnings 
of migration and the earnings differential in favor of migrants. My findings do not support the conventional wisdom that migrants constitute a positive selected subsample of the population. After controlling for the observed characteristics of individuals and after incorporating other explanatory variables which may serve as a proxy for differences in log earnings, there is little variability between the earnings of migrants and stayers to be explained by unobservable traits.

\subsection{Estimates of the probability of migrating}

Table 6 records the estimates of the probability of migrating. Besides the variables in the earnings equations, I include dummies for the years of residence in the current state among the regressors to capture state dependence, and dummies for the states of origin as a proxy for amenity differences as perceived by the individuals. For the sake of brevity, the coefficients of the state dummies are not reported.

Surprisingly, the dummies associated with years of residence, with the exception of the one corresponding to 10 years or more in the current state, are not significantly different from zero at conventional levels. This is partially at odds with the hypothesis that as the number of years in a given state increases, people become less likely to move.

People living in rural areas, working in the agricultural sector or in the public administration are less likely to move, as indicated by the dummy coefficients, which are negative and statistically significant. The results also suggest that selfemployed individuals and those employed in the informal sector are less likely to move, despite the small magnitude of the coefficients.

Finally, there is evidence that the more educated are more prone to move, as indicated by the coefficients of 13 or more years of schooling, which are statistically significant at the $10 \%$ level.

\subsection{Coefficients of earnings of migrants}

Having described the determinants of the probability of migrating, I turn now to the analysis of the variables affecting the earnings of migrants. The results are summarized in Table 7. I suppress again the coefficients of the state dummies. Almost all the coefficients are statistically significant at conventional levels and have the expected sign. The estimates provide evidence of nonlinearity in returns to schooling, especially for those with at least a high school degree, and of concavity of log earnings in experience.

The coefficients of the other variables have also the expected sign. If the individual is black or brown and lives in the rural area, for instance, we observe a reduction in predicted log earnings. In contrast, if the person is a member of a trade union or works in the public administration, the predicted earnings are higher.

Finally, it is worth noting the negative coefficient of the inverse Mills ratio, 
Table 6

Estimated coefficients - Probability of migration

\begin{tabular}{|c|c|c|c|}
\hline Variable & Estimated coefficient & Standard error & $P$ value \\
\hline Constant & -0.366 & 0.094 & 0.000 \\
\hline Experience & 0.019 & 0.002 & 0.000 \\
\hline Experience squared & 0.000 & 0.000 & 0.011 \\
\hline Unionized & -0.028 & 0.018 & 0.112 \\
\hline Rural area & -0.219 & 0.024 & 0.000 \\
\hline \multicolumn{4}{|l|}{ Years of Schooling } \\
\hline 1 & 0.022 & 0.044 & 0.618 \\
\hline 2 & 0.029 & 0.037 & 0.428 \\
\hline 3 & -0.017 & 0.033 & 0.610 \\
\hline 4 & -0.003 & 0.028 & 0.907 \\
\hline 5 & 0.124 & 0.033 & 0.000 \\
\hline 6 & 0.038 & 0.040 & 0.345 \\
\hline 7 & 0.061 & 0.040 & 0.128 \\
\hline 8 & 0.066 & 0.032 & 0.037 \\
\hline 9 & 0.047 & 0.049 & 0.341 \\
\hline 10 & 0.101 & 0.046 & 0.028 \\
\hline 11 & 0.093 & 0.031 & 0.003 \\
\hline 12 & 0.027 & 0.069 & 0.695 \\
\hline 13 & 0.213 & 0.073 & 0.003 \\
\hline 14 & 0.146 & 0.079 & 0.064 \\
\hline 15 or more & 0.222 & 0.040 & 0.000 \\
\hline \multicolumn{4}{|l|}{ Race } \\
\hline Indian & 0.278 & 0.170 & 0.101 \\
\hline Black & -0.024 & 0.027 & 0.380 \\
\hline Yellow & 0.163 & 0.111 & 0.141 \\
\hline Brown & 0.026 & 0.016 & 0.111 \\
\hline \multicolumn{4}{|l|}{ Occupation } \\
\hline Employee informal sector & -0.061 & 0.019 & 0.002 \\
\hline Public sector worker & -0.015 & 0.039 & 0.703 \\
\hline Self-employed & -0.074 & 0.019 & 0.000 \\
\hline Employer & -0.011 & 0.030 & 0.707 \\
\hline \multicolumn{4}{|l|}{ Years in the current state } \\
\hline 1 & -0.036 & 0.106 & 0.738 \\
\hline 2 & -0.113 & 0.104 & 0.277 \\
\hline 3 & -0.034 & 0.106 & 0.746 \\
\hline 4 & -0.126 & 0.109 & 0.245 \\
\hline 5 & -0.134 & 0.105 & 0.203 \\
\hline 6 & -0.120 & 0.106 & 0.258 \\
\hline 7 & -0.071 & 0.109 & 0.515 \\
\hline 8 & -0.023 & 0.108 & 0.835 \\
\hline 9 & 0.109 & 0.121 & 0.371 \\
\hline 10 or more & -1.278 & 0.085 & 0.000 \\
\hline \multicolumn{4}{|l|}{ Sector of Activity } \\
\hline Agriculture & -0.112 & 0.027 & 0.000 \\
\hline Civil construction & 0.005 & 0.025 & 0.844 \\
\hline Services & 0.007 & 0.019 & 0.719 \\
\hline Public administration & -0.159 & 0.041 & 0.000 \\
\hline Number of Observations & & 75,513 & \\
\hline Pseudo $\mathrm{R}^{2}$ & & 0.380 & \\
\hline
\end{tabular}

This table shows the estimated coefficients of the probit model for the probability of migration, their standard errors and associated $p$-values. The dependent variable equals 1 if the person is a migrant and zero otherwise. The following Paulo), occupation (employee formal sector), years in the current state (less than 1), state of origin (São Paulo) and sector of activity (industry). 
which is barely significant at the $10 \%$ level. A negative estimate of the covariance between earnings of migrants and the disturbance affecting the probability of migrating implies that self-selection causes the mean of log wages of migrants to fall short of the mean of log wages in the population. In the sequel, I address this question in more detail and relate my findings to the results encountered in the literature.

Table 7

Estimated Coefficients - Earnings equation - Migrants

\begin{tabular}{|c|c|c|c|}
\hline Variable & Estimated coefficient & Standard error & $P$ value \\
\hline Constant & 1.599 & 0.036 & 0.000 \\
\hline Experience & 0.044 & 0.002 & 0.000 \\
\hline Experience squared & -0.001 & 0.000 & 0.000 \\
\hline Unionized & 0.177 & 0.015 & 0.000 \\
\hline Rural area & -0.155 & 0.021 & 0.000 \\
\hline \multicolumn{4}{|l|}{ Years of Schooling } \\
\hline 1 & 0.153 & 0.037 & 0.000 \\
\hline 2 & 0.168 & 0.030 & 0.000 \\
\hline 3 & 0.217 & 0.027 & 0.000 \\
\hline 4 & 0.340 & 0.023 & 0.000 \\
\hline 5 & 0.372 & 0.027 & 0.000 \\
\hline 6 & 0.437 & 0.032 & 0.000 \\
\hline 7 & 0.496 & 0.032 & 0.000 \\
\hline 8 & 0.581 & 0.026 & 0.000 \\
\hline 9 & 0.616 & 0.041 & 0.000 \\
\hline 10 & 0.693 & 0.038 & 0.000 \\
\hline 11 & 0.922 & 0.025 & 0.000 \\
\hline 12 & 1.275 & 0.057 & 0.000 \\
\hline 13 & 1.484 & 0.059 & 0.000 \\
\hline 14 & 1.500 & 0.065 & 0.000 \\
\hline 15 or more & 1.976 & 0.032 & 0.000 \\
\hline \multicolumn{4}{|l|}{ Race } \\
\hline Indian & 0.009 & 0.117 & 0.940 \\
\hline Black & -0.137 & 0.025 & 0.000 \\
\hline Yellow & 0.182 & 0.084 & 0.030 \\
\hline Brown & -0.151 & 0.012 & 0.000 \\
\hline \multicolumn{4}{|l|}{ Occupation } \\
\hline Employee informal sector & -0.180 & 0.016 & 0.000 \\
\hline Public sector worker & 0.209 & 0.032 & 0.000 \\
\hline Self-employed & -0.069 & 0.015 & 0.000 \\
\hline Employer & 0.614 & 0.024 & 0.000 \\
\hline \multicolumn{4}{|l|}{ Sector of Activity } \\
\hline Agriculture & -0.232 & 0.023 & 0.000 \\
\hline Civil construction & -0.134 & 0.021 & 0.000 \\
\hline Services & -0.093 & 0.016 & 0.000 \\
\hline Public administration & 0.103 & 0.033 & 0.002 \\
\hline Mills ratio & -0.017 & 0.010 & 0.100 \\
\hline$\sigma_{11}$ & 0.478 & & \\
\hline Number of Observations & & 15,623 & \\
\hline $\mathrm{R}^{2}$ & & 0.475 & \\
\hline
\end{tabular}

This table shows the estimated coefficients of the earnings equation of migrants, their standard errors and associated $p$-values. The dependent variable is the logarithm of the hourly wage. Hourly wage equals earnings from all jobs in the week in which the survey was conducted divided by the number of hours worked in the same week. The following Paulo), occupation (employee formal sector), and sector of activity (industry). 


\subsection{Coefficients of earnings of stayers}

Overall, the estimates for stayers recorded in Table 8 are very similar to the ones obtained for migrants. Experience, for instance, has exacly the same impact on log earnings. We also see that unionized workers have on average a greater salary than nonunionized individuals and that people living in the rural area earn a lower wage than workers in the urban area.

A few differences, however, are noteworthy. Both the constant and all the dummies associated with the several schooling categories are slightly lower for stayers, suggesting that the impact of one year of additional schooling is higher for migrants.

The estimated coefficient of the inverse Mills ratio is displayed at the bottom of the table, along with the standard error and the corresponding p-value. The estimate has the opposite sign to that of migrants and it is a bit higher in absolute value, although now it is not significantly different from zero.

\subsection{Evidence of the impact of migration on earnings}

Table 9 compiles the six measures of the impact of migration on earnings expounded in subsection 3.3. In the first row of the table we have the average realized earnings gain or average treatment effect. Since this is an average across all individuals in the population, there is no issue regarding selection bias in its construction. The estimates suggest that on average log earnings are 0.1120 higher at the best destination than at the place of birth.

The returns to migration, shown in the second row of the table, equal 0.0772 and are positive, as expected, implying that the logarithm of wages of a typical migrant is higher than what she would receive at the origin. Conversely, the returns to staying are negative. More precisely, they equal -0.1211 . As pointed out above, this is consistent with the paradigm of a rational individual. The magnitude, almost twice greater in absolute value than the returns to migration, indicates that the stayers face a substantially higher cost of switching states than do migrants, preventing them from moving to a location where they would receive a higher compensation.

Turning to the selection of migrants, the results reveal that the difference in the mean of unobservables of migrants and stayers affecting log earnings at the destination is -0.0255 . The number is negative and quite small, derived from the negative and barely statistically significant estimated coefficient of the inverse Mills ratio in the equation of log earnings. Hence, there is strong evidence against the presumption that migrants are a positive selected subsample of the population. In other words, after controlling for all observable variables that may explain the variability in log earnings, there is no evidence of a difference attributable to unobservable traits of migrants which make them more productive at the destination than observationally equivalent non-migrants.

The results reported in the previous subsection also imply that the mean of 
Table 8

Estimated Coefficients - Earnings equation - Stayers

\begin{tabular}{|c|c|c|c|}
\hline Variable & Estimated coefficient & Standard error & $P$ value \\
\hline Constant & 1.553 & 0.019 & 0.000 \\
\hline Experience & 0.044 & 0.001 & 0.000 \\
\hline Experience squared & -0.001 & 0.000 & 0.000 \\
\hline Unionized & 0.141 & 0.008 & 0.000 \\
\hline Rural area & -0.078 & 0.010 & 0.000 \\
\hline \multicolumn{4}{|l|}{ Years of Schooling } \\
\hline 1 & 0.065 & 0.019 & 0.001 \\
\hline 2 & 0.102 & 0.016 & 0.000 \\
\hline 3 & 0.176 & 0.014 & 0.000 \\
\hline 4 & 0.273 & 0.012 & 0.000 \\
\hline 5 & 0.305 & 0.014 & 0.000 \\
\hline 6 & 0.393 & 0.017 & 0.000 \\
\hline 7 & 0.460 & 0.016 & 0.000 \\
\hline 8 & 0.538 & 0.014 & 0.000 \\
\hline 9 & 0.594 & 0.019 & 0.000 \\
\hline 10 & 0.677 & 0.019 & 0.000 \\
\hline 11 & 0.867 & 0.013 & 0.000 \\
\hline 12 & 1.241 & 0.027 & 0.000 \\
\hline 13 & 1.318 & 0.029 & 0.000 \\
\hline 14 & 1.470 & 0.032 & 0.000 \\
\hline 15 or more & 1.919 & 0.018 & 0.000 \\
\hline \multicolumn{4}{|l|}{ Race } \\
\hline Indian & -0.107 & 0.066 & 0.104 \\
\hline Black & -0.153 & 0.012 & 0.000 \\
\hline Yellow & -0.034 & 0.053 & 0.518 \\
\hline Brown & -0.101 & 0.007 & 0.000 \\
\hline \multicolumn{4}{|l|}{ Occupation } \\
\hline Employee informal sector & -0.208 & 0.008 & 0.000 \\
\hline Public sector worker & 0.159 & 0.016 & 0.000 \\
\hline Self-employed & -0.103 & 0.008 & 0.000 \\
\hline Employer & 0.574 & 0.013 & 0.000 \\
\hline \multicolumn{4}{|l|}{ Sector of Activity } \\
\hline Agriculture & -0.317 & 0.012 & 0.000 \\
\hline Civil construction & -0.075 & 0.011 & 0.000 \\
\hline Services & -0.042 & 0.008 & 0.000 \\
\hline Public administration & 0.122 & 0.016 & 0.000 \\
\hline Mills ratio & 0.020 & 0.024 & 0.407 \\
\hline$\sigma_{00}$ & 0.460 & & \\
\hline Number of Observations & & 59,890 & \\
\hline $\mathrm{R}^{2}$ & & 0.442 & \\
\hline
\end{tabular}

This table shows the estimated coefficients of the earnings equation of stayers, their standard errors and associated $p$-values. Hourly wage equals earnings from all jobs in the week in which the survey was conducted divided by the number of hours worked in the same week. The following dummies were excluded to avoid multicollinearity: years of
schooling (less than 1), race (white), state of residence (São Paulo), occupation (employee formal sector), and sector of activity (industry). 
unobservables of stayers at the origin falls short of the population mean (Recall that $\lambda(-Z \gamma)$, which is positive, enters with a negative sign in equation (3)). The average reduction in the logarithm of earnings of stayers, in comparison with what migrants would earn had they stayed, corresponds to -0.0184 , according to Table 9. This last measure is negative, rather modest and based on an estimated value of $\sigma_{0 v}$ that is not statistically different from zero. In sum, the results suggest that neither migrants nor stayers compose a positive selected subsample of the population.

Table 9

Estimates of the impact of migration on log earnings

\begin{tabular}{ccc}
\hline Statistic & Definition & Estimate \\
\hline Average realized gain & $E\left(y_{1}\right)-E\left(y_{0}\right)$ & 0.1120 \\
Returns to migration & $E\left(y_{1} \mid I=1\right)-E\left(y_{0} \mid I=1\right)$ & 0.0772 \\
Returns to staying & $E\left(y_{0} \mid I=0\right)-E\left(y_{1} \mid I=0\right)$ & -0.1211 \\
Selection of migrants & $E\left(u_{1} \mid I=1\right)-E\left(u_{1} \mid I=0\right)$ & -0.0255 \\
Selection of stayers & $E\left(u_{0} \mid I=0\right)-E\left(u_{0} \mid I=1\right)$ & -0.0184 \\
Earnings differential & $E\left(y_{1} \mid I=1\right)-E\left(y_{0} \mid I=0\right)$ & 0.0956 \\
in favor of migrants & & \\
\hline
\end{tabular}

This table shows the estimates of the six measures of the impact of migration on earnings, presented in Table 5. The values are computed using the two-step estimates of the earnings equations of migrants and stayers.

How can we reconcile these results with previous findings of the literature (e.g., Borjas, 1987, Chiswick, 1999, Santos Jr et al., 2005), which conclude that the higher wages of migrants are a consequence of differences in unobservable characteristics? If we inappropriately restrict the coefficients of the observable covariates in the earnings equations to be the same when they are in fact distinct, the difference is absorbed by the error term, leading to biased inferences. In the case under consideration, in which the constant and the coefficients of the dummies associated with years of schooling are uniformly higher at the destination than at the origin and there is weak evidence of self-selection, the restriction would lead us to conclude that the mean of unobservables of migrants exceeds the population mean. The inclusion of a dummy variable for migrants captures this effect, reflecting the differences in the coefficients of the explanatory variables which were constrained to be equal and not a true difference between unobservables of migrants and stayers.

To gain further insight into the effect of migration on earnings, it is instructive to compare the average realized earnings gain discussed above with "the effect of migration status on earnings" reported by Santos Jr et al. (2005). The discussion in the previous paragraph suggests that the two measures must be close to each other. The estimate of the average realized gain of 0.1120 , presented in Table 9 , 
concurs with their estimates, which range from 0.0854 to $0.1508 .^{10}$

Finally, I consider the earnings differential in favor of migrants, displayed at the bottom of Table 9. Recall that this measure compares the average earnings of migrants with the average earnings of stayers, incorporating the effect of unobservable heterogeneity. The value of 0.0956 is roughly $15 \%$ smaller than the average realized earnings, confirming a difference in the unobservables of the two subgroups in favor of stayers.

\section{Conclusion}

In this paper, I proposed and estimated a comparative advantage model of migration in which heterogeneous individuals decide to move if log earnings at the destination, net of moving costs, exceed log earnings at the origin. I used the estimates from a probit equation that proxies the decision rule of the agent to control for unobserved heterogeneity in earnings. Then, I considered six measures that shed light on the effect of migration on earnings and on the issue of selfselection.

The majority of migrants is gathered in the Southeast, especially in São Paulo, while most stayers live in the Northeast. My results indicate that an individual randomly selected from the population receives on average a significant higher compensation at the best destination than at the origin and suggest that the increase in earnings that emerges from migration is attributable to observable individual characteristics and to other observed variables which capture differences across jobs.

Furthermore, the substantial costs of moving that some workers face and the negative payoff associated with their decision to relocate prevent them from leaving their place of birth. As a result, a fraction of workers ends up receiving a smaller compensation at the origin than they would receive had they migrated. These workers do not come from the lower tail of the income distribution.

Thus, my findings do not support the widespread view that migrants have unobservable traits which make them more productive than stayers, at least after controlling for observables.

\section{References}

Azzoni, C., Carmo, H., \& Menezes, T. (2002). Comparações da paridade do poder de compra entre cidades: Aspectos metodológicos e aplicação ao caso brasileiro. Pesquisa e Planejamento Econômico, 33(1):91-126.

Borjas, G. (1987). Self-selection and the earnings of immigrants. American Economic Review, 77(4):531-553.

\footnotetext{
${ }^{10}$ The estimates are not strictly comparable. The authors use a subsample including both males and females and, as pointed out previously, restrict the unobservables and the coefficients of observables at the origin and at the destination to be the same.
} 
Chiswick, B. (1978). The effect of Americanization on the earnings of foreign-born men. Journal of Political Economy, 86(5):897-921.

Chiswick, B. (1999). Are immigrants favorably self-selected? American Economic Review, 89(2):181-185.

Heckman, J. (1979). Sample selection bias as a specification error. Econometrica, 47(1):153-161.

Heckman, J. \& Honore, B. (1990). The empirical content of the Roy model. Econometrica, 58(5):1121-1149.

Heckman, J., Lochner, L., \& Todd, P. (2002). Fifty years of Mincer regressions. Unpublished manuscript, University of Chicago.

Heckman, J. \& Sedlacek, G. (1985). Heterogeneity, aggregation and market wage functions: An empirical model of self-selection in the labor market. Journal of Political Economy, 93(6):1077-1125.

Menezes, T., Azzoni, C., \& Moreira, G. (2007). Diferenças em gastos de aluguel entre os estados, tipos de área e níveis de renda familiar no Brasil. In Silveira, F., Servo, L., Menezes, T., \& Piola, S., editors, Gasto e Consumo das Familias Brasileiras Contemporâneas, pages 237-247. IPEA, Brasília.

Newey, W. \& McFadden, D. (1994). Large sample estimation and hypothesis testing. In Engle, R. \& McFadden, D., editors, Handbook of Econometrics, pages 2111-2245. North-Holland, Amsterdam.

Quandt, R. (1972). A new approach to estimating switching regressions. Journal of the American Statistical Association, 67(338):306-310.

Roy, A. (1951). Some thoughts on the distribution of earnings. Oxford Economic Papers, 3(2):135-146.

Santos Jr, E., Menezes Filho, N., \& Ferreira, P. (2005). Migração, seleção e diferenças regionais de renda no Brasil. Pesquisa e Planejamento Econômico, $35(3): 299-332$.

Sjaastad, L. (1962). The costs and returns of human migration. Journal of Political Economy, Supplement, 70(5):80-93.

Tunali, I. (2000). Rationality of migration. International Economic Review, $41(4): 893-920$.

Willis, R. \& Rosen, S. (1979). Education and self-selection. Journal of Political Economy, 87(5):S7-S36. 